\title{
An SDE Study of Twin-wire Electric Arc Sprayed Nickel-Aluminum Coatings
}

\author{
D. J. Varacalle, Jr., G. C. Wilson \\ Vartech, Inc. \\ Idaho Falls, Idaho 83415
}

\author{
L. B. Lundberg, D. L. Hale \\ Idaho National Engineering Laboratory \\ Idaho Falls, Idaho 83415
}

\author{
V. Zanchuck, W. Kratochvil, G. Irons, A. Hodum \\ Tafa, Inc. \\ Concord, New Hampshire 03301
}

\begin{abstract}
An analytical and experimental study of the twin-wire electric arc spraying of nickel-aluminum coatings has been performed to demonstrate the suitability of the wire system as a bond coat material for ceramic overcoats in thermal barrier applications, and for spraying a single coat for part refurbishment. Experiments were conducted using a Box-type full-factorial design parametric study. Operating parameters were varied around the typical process parameters (i.e., current, primary and secondary pressure, spray distance) in a systematic design of experiments (SDE) in order to display the range of processing conditions and their effect on the resultant coating. The coatings were characterized by hardness tests and optical metallography. Coating properties were quantified for hardness, porosity, deposition efficiency, and microstructure. The features of the coatings are correlated with the changes in operating parameters. Analytical calculations of the gas and droplet dynamics are presented, which includes molten metal entrainment and droplet breakup models.
\end{abstract}

The twin-wire electric arc (TWEA) spray process can be traced back to 1914,(1) when Schoop and his colleague Bauerlin performed their initial experiments with electric heating wires. Subsequent design involved the use of two wires that were electrically insulated and brought together downstream of an orifice.

The key advantages of the TWEA process are higher output and lower cost than other processes. In the process, two wires are brought together and an electric arc is struck between them. Typical dc voltages are $20-35$ volts, with current ranging up to 350 amperes and in some cases more. Wire feedrate is governed by the system current. The arc developed between the two wires causes the wire tips to melt. An atomizing gas, typically air, is delivered to these two wires in such a way as to strip off small droplets of molten metal. In this way, kinetic energy is transferred to the droplets. Typical air flow rate ranges from 30 to 60 standard cubic feet per minute (scfm). It is not uncommon to spray with either nitrogen or argon in an attempt to reduce the formation of oxides on the molten droplets. In general, any material that is electrically conductive and can be made into a wire can be sprayed with a TWEA device.

Nickel-aluminum coatings find widespread applications in the automotive, transportation, aerospace, and aircraft industries. The nickel-aluminum material system is used in applications for restoration of dimension, wear, and oxidation and is used extensively as bond coats for thermal-sprayed ceramic coatings to enhance the adhesion strength of the coating to the substrate. Low porosity and oxide content, high roughness, and low residual stresses in the coating are required for maximum bond strength. The TWEA process was chosen for this application because of the capability of attaining high purity nickel-aluminum coatings with high bond and interparticle strengths.

This study attempted to further the understanding of the mechanisms involved in the formation of TWEA coatings by determining analytically how process parameter variations affect the process dynamics and determining empirically which processing parameters affect the structure and properties of the coatings.

\section{Experimental Procedure}

A Tafa, Inc. Model 9000 TWEA spray system and commercially available nickel-aluminum wire were used for this study (Tafa 75B). A Box-type, full-factorial design of experiment(2) was conducted. The Box analysis was accomplished with the Design-Ease(3) software package on the measured responses.

Experiments NA01-NA22, illustrated in Table 1, represent the full-factorial design. Each variable has two

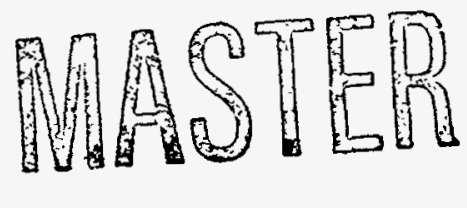


levels selected to band around the nominal settings (i.e., experiments NA17-NA19) to demonstrate the processing capabilities at a variety of stable thermal conditions. The process parameters varied were current, primary and secondary air flow, and spray distance. The resulting responses evaluated were thickness using optical microscopy, superficial hardness with a Rockwell $15 \mathrm{~N}$ test, Vickers microhardness, porosity and oxide content derived from image analysis, roughness, and deposition efficiency (DE).

Air was used as the primary and shroud gas. Wire injection was internal to the gun and directed parallel to the flow. The wire feedrates were $8.4 \mathrm{lb} / \mathrm{hr}$ for the 100 -ampere experiments, $13.9 \mathrm{lb} / \mathrm{hr}$ for the 175-ampere experiments, $17.9 \mathrm{lb} / \mathrm{hr}$ for the 200 -ampere experiments, and $29.5 \mathrm{lb} / \mathrm{hr}$ for the 300-ampere experiments. An $x-y$ servo-manipulator ensured the standoff distance and repeatability in the experiments. The traverse $\mathrm{x}$-motion rate was $20 \mathrm{in}$. $/ \mathrm{sec}$. A $\mathrm{y}$-step of 0.125 in. was used. Sixteen traverses per pass were utilized. Four passes were used to fabricate the 100-ampere coatings, three passes were used to fabricate the 175- and 200-ampere coatings, and 2 passes were used to fabricate the 300 -ampere coatings. A system voltage of 31 volts was used for all the experiments. The wire was thermal sprayed onto 6061 aluminum coupons ( $4 \times 6 \times 0.125$ in.) cooled by air jets on the back side. The deposition side of each coupon was

Table 1. Nickel-Aluminum TWEA Experiments.

\begin{tabular}{lcccc}
\hline & $\begin{array}{c}\text { Gun } \\
\text { Current } \\
\text { Exp. \# }\end{array}$ & $\begin{array}{c}\text { Primary P } \\
\text { (amsia) }\end{array}$ & $\begin{array}{c}\text { Secondary P } \\
\text { (psia) }\end{array}$ & $\begin{array}{c}\text { Spray Dist. } \\
\text { (in.) }\end{array}$ \\
\hline NA01 & 100 & 50 & 50 & 3.0 \\
NA02 & 300 & 50 & 50 & 3.0 \\
NA03 & 100 & 70 & 50 & 3.0 \\
NA04 & 300 & 70 & 50 & 3.0 \\
NA05 & 100 & 50 & 70 & 3.0 \\
NA06 & 300 & 50 & 70 & 3.0 \\
NA07 & 100 & 70 & 70 & 3.0 \\
NA08 & 300 & 70 & 70 & 3.0 \\
NA09 & 100 & 50 & 50 & 6.0 \\
NA10 & 300 & 50 & 50 & 6.0 \\
NA11 & 100 & 70 & 50 & 6.0 \\
NA12 & 300 & 70 & 50 & 6.0 \\
NA13 & 100 & 50 & 70 & 6.0 \\
NA14 & 300 & 50 & 70 & 6.0 \\
NA15 & 100 & 70 & 70 & 6.0 \\
NA16 & 300 & 70 & 70 & 6.0 \\
NA17 & 200 & 60 & 60 & 4.5 \\
NA18 & 200 & 60 & 60 & 4.5 \\
NA19 & 200 & 60 & 60 & 4.5 \\
NA20 & 175 & 60 & 60 & 3.0 \\
NA21 & 175 & 60 & 60 & 4.5 \\
NA22 & 175 & 60 & 60 & 6.0 \\
\hline & & & &
\end{tabular}

grit blasted with No. 30 alumina grit prior to spraying that surface.

\section{Coating Characterization}

The coatings were characterized with measurements of thickness, microhardness, porosity +oxide content, DE, and roughness. Attributes were measured on metallographically prepared cross-sections of each coating. Results of these measurements are listed in Table 2.

The coating thickness values were derived from measurements made under an optical metallurgical microscope at $200 \mathrm{X}$ magnification using a filar eyepiece. The thickness values listed in Table 2 represent an average of twelve measurements at different locations on the coating crosssection. Thickness ranged from 9 to 21 mils. The thickness per pass ranged from 2.25 to 10.5 mils/pass. The highest deposition rates were achieved at the highest power levels.

Microhardness measurements were taken on a cross-section through the coating. Five measurements were taken and averaged. The microhardness measurements ranged from 129 to 205 (i.e., HV300).

Image analysis procedures were used for measuring coating porosity plus oxide content. Due to an inability to calibrate the technique, the values of the attributes tend to be highly subjective relative to differentiation among the various microstructural features. Thus, one cannot easily distinguish between either porosity or oxide content. The total porosity +oxide content for each coating is listed in Table 2, and ranged from 7 to $19 \%$. Estimates of the separate porosity and oxide content levels were made by analyzing the photomicrographs for porosity, and then subtracting the estimated porosity value from the measured porosity +oxide value. These values are also included in Table 2. The average coating porosity was estimated to range from 2.5 to $8.3 \%$, while the average coating oxide content ranged from 2 to $14 \%$. Rough hand measurements of areas occupied by the features were also calculated, and indicated that from 15 to $40 \%$ of the volume of a typical coating was either pores or oxide phases as illustrated in Figures 1 and 2. For enhanced bond strength, low porosity and oxide content are required, which can be produced with spraying conditions of higher current, shorter spray distance, and lower atomizing air pressure.(4)

$D E$ for the experiments was determined with conventional techniques by weighing the amount of sprayed metal deposited on the substrate for a prescribed time. The DEs ranged from 55.8 to $76.9 \%$.

Coating roughness was determined with surface profilometry. The roughness of the coatings ranged from 388 to 676 microinches $R_{2}$ (higher values are rougher). For enhanced bond strength, rougher coatings are required, which can be produced when larger particles impact the substrate with lower velocities. Spraying conditions of higher current, shorter spray distance, and lower atomizing air pressure produce rougher coatings. 
Table 2. Coating Characterization Results for Experiments NA01-NA22.

\begin{tabular}{|c|c|c|c|c|c|c|c|c|}
\hline $\begin{array}{l}\text { Exp. } \\
\#\end{array}$ & mils & $\begin{array}{l}\text { mils/pass }\end{array}$ & Hardness & $\begin{array}{c}\text { Por. + Ox. } \\
\%\end{array}$ & $\begin{array}{c}\text { Porosity } \\
\%\end{array}$ & $\begin{array}{c}\text { Oxides } \\
\%\end{array}$ & $\begin{array}{r}\mathrm{DE} \\
\%\end{array}$ & $\begin{array}{l}\text { Roughness } \\
\text { microinch }\end{array}$ \\
\hline NA01 & 12 & 3.00 & 147 & 14 & 5.8 & 8.2 & 66.8 & 554 \\
\hline NA02 & 20 & 10.00 & 205 & 10 & 8.0 & 2.0 & 76.9 & 640 \\
\hline NA03 & 11 & 2.75 & 155 & 9 & 2.5 & 6.5 & 65.3 & 518 \\
\hline NA04 & 19 & 9.50 & 164 & 7 & 4.3 & 2.7 & 71.7 & 588 \\
\hline NA05 & 11 & 2.75 & 129 & 13 & 8.0 & 5.0 & 64.4 & 538 \\
\hline NAOG & 21 & 10.50 & 184 & 13 & 4.0 & 9.0 & 74.3 & 676 \\
\hline NA07 & 11 & 2.75 & 139 & 14 & 6.3 & 7.7 & 61.0 & 484 \\
\hline NA08 & 20 & 10.00 & 175 & 10 & 2.8 & 7.2 & 70.7 & 622 \\
\hline NA09 & 10 & 2.50 & 146 & 13 & 4.5 & 8.5 & 61.0 & 508 \\
\hline NA10 & 18 & 9.00 & 190 & 10 & 7.3 & 2.7 & 68.7 & 566 \\
\hline NA11 & 10 & 2.50 & 164 & 8 & 3.0 & 5.0 & 60.3 & 412 \\
\hline NA12 & 16 & 8.00 & 165 & 18 & 6.0 & 12.0 & 66.0 & 504 \\
\hline NA13 & 10 & 2.50 & 136 & 13 & 7.8 & 5.2 & 60.1 & 486 \\
\hline NA14 & 17 & 8.50 & 200 & 12 & 7.3 & 4.7 & 67.6 & 560 \\
\hline NA15 & 9 & 2.25 & 134 & 11 & 3.5 & 7.5 & 55.3 & 388 \\
\hline NA16 & 17 & 8.50 & 184 & 19 & 6.8 & 12.2 & 65.0 & 550 \\
\hline NA17 & 16 & 5.33 & 184 & 18 & 4.0 & 14.0 & 66.9 & 544 \\
\hline NA18 & 15 & 5.00 & 164 & 16 & 8.3 & 7.7 & 66.1 & 478 \\
\hline NA19 & 15 & 5.00 & 162 & 14 & 4.5 & 9.5 & 66.3 & 486 \\
\hline NA20 & 14 & 4.67 & 171 & 9 & 5.8 & 3.2 & 75.1 & 534 \\
\hline NA21 & 13 & 4.33 & 163 & 17 & 5.5 & 11.5 & 70.9 & 550 \\
\hline NA22 & 12 & 4.00 & 157 & 17 & 4.0 & 13.0 & 67.9 & 436 \\
\hline
\end{tabular}

a. Vickers microhardness values ( 300 gram load)

The microstructure of coating sample NA08, illustrated in Figure 1, is representative of the coatings with the least amount of pores or oxide phases, while the microstructure of coating sample NA18, illustrated in Figure 2, is representative of the coatings with the largest amount of pores or oxide phases. The combination of 50 psi primary and shroud pressure, current of 300 amperes, and a 3-in. spray distance produced coatings with the lowest porosity +oxide content, the highest roughness, and the highest DE for the study.

\section{Discussion of Box Full-Factorial Experiment Design}

The Box-type statistical design of experiment (SDE) methodology is an efficient means of determining broad-based factor effects on measured attributes. This methodology statistically delineates the impact of each variable on the measured coating characteristics across all combinations of other factors. The I percent (I\%) calculation indicates the influence of a factor or parameter on the measured response, with a larger number indicating more influence. The analysis of variance (ANOVA) calculations guide further experimentation by indicating which parameters are the most influential on coating attributes.
For this particular bond coat application, the optimum coating is derived from those conditions that dictate high bond strength. Bond strength is enhanced by high surface roughness, low porosity and oxide content, and low residual stress levels in the coating. Table 3 illustrates the results of the Box analysis.

Table 3. Results of the Box Analysis.

\begin{tabular}{|c|c|c|c|c|}
\hline Processing Factor: & Current & $\begin{array}{l}\text { Primary } \\
P\end{array}$ & $\begin{array}{l}\text { Secondary } \\
\mathbf{P}\end{array}$ & $\begin{array}{l}\text { Spray } \\
\text { Dist. }\end{array}$ \\
\hline esired Attribute & I\%/level & I\%/level & I\%/level & I\%/level \\
\hline 1 High Roughness & $45.0 /+1$ & 14.0 & $0.0 /+1$ & $32.2 /-1$ \\
\hline 2 Low Por +Ox & $0.3 /+1$ & $0.2 /-1$ & $9.4 /-1$ & $15.9 /-1$ \\
\hline 3 High DE & $51.5 /+1$ & $7.6 /-1$ & & $33.9 /-1$ \\
\hline 4 High Mic.hard. & $71.4 /+1$ & $2.3 /-1$ & $2.2 /-1$ & $0.0 /+1$ \\
\hline
\end{tabular}

High roughness was most influenced by system amperage and spray distance. Higher amperage results in rougher coatings as indicated by an I\% of $45 \%$. The other main contributor is spray distance at a $32.21 \%$, with shorter spray distances resulting in rougher coatings. 


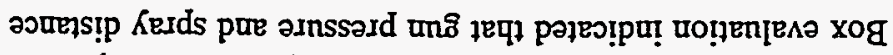

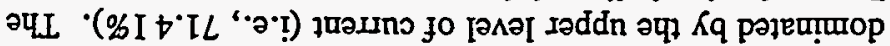

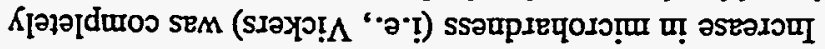

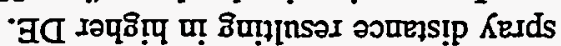

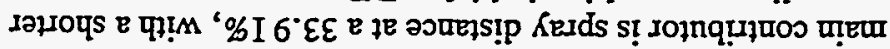

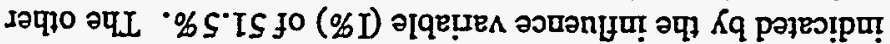

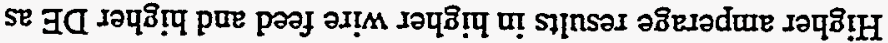

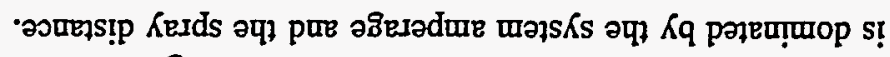

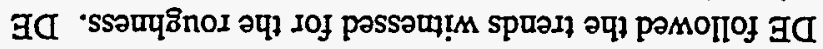

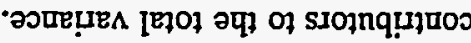

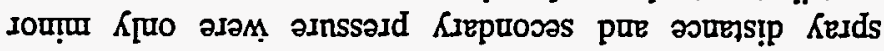

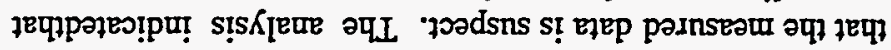

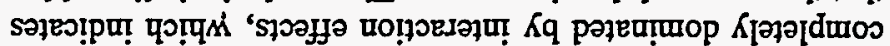

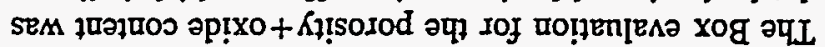

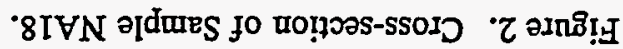

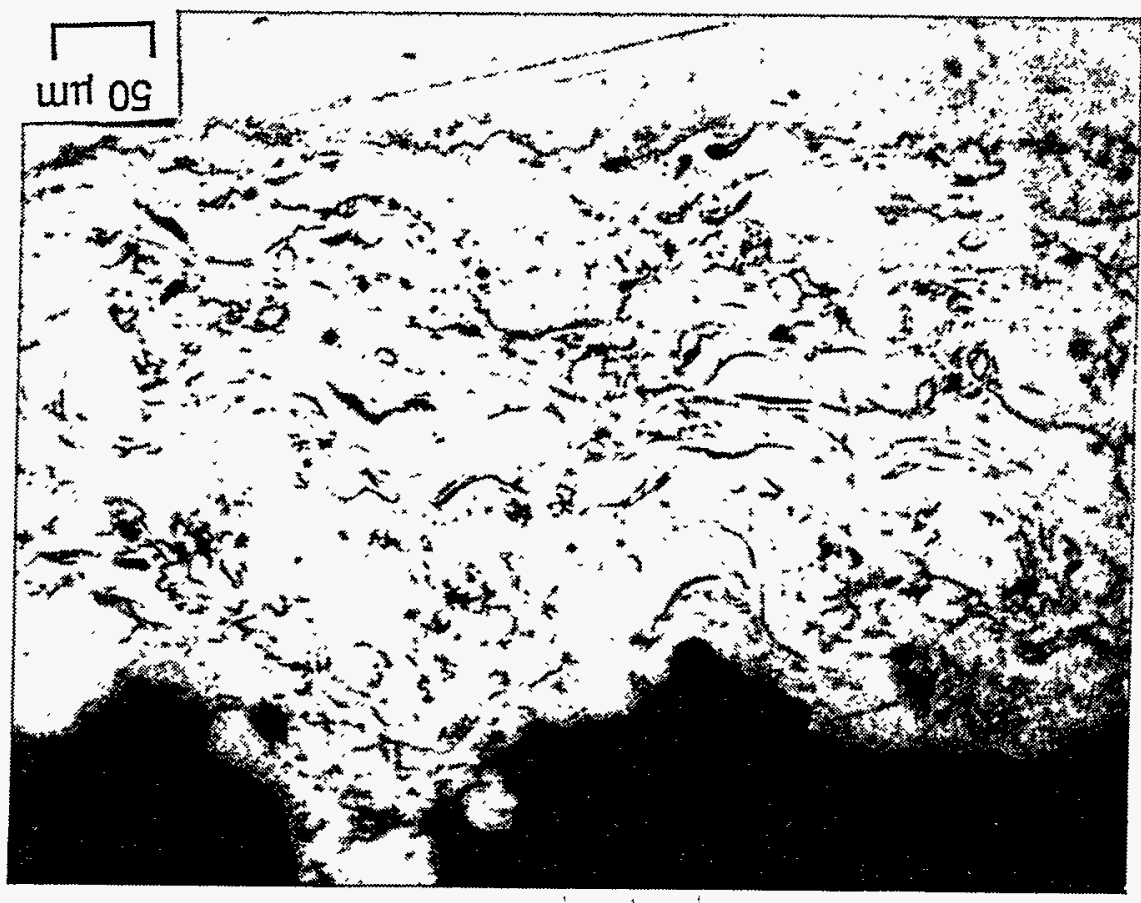

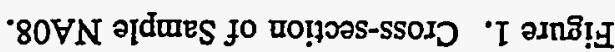

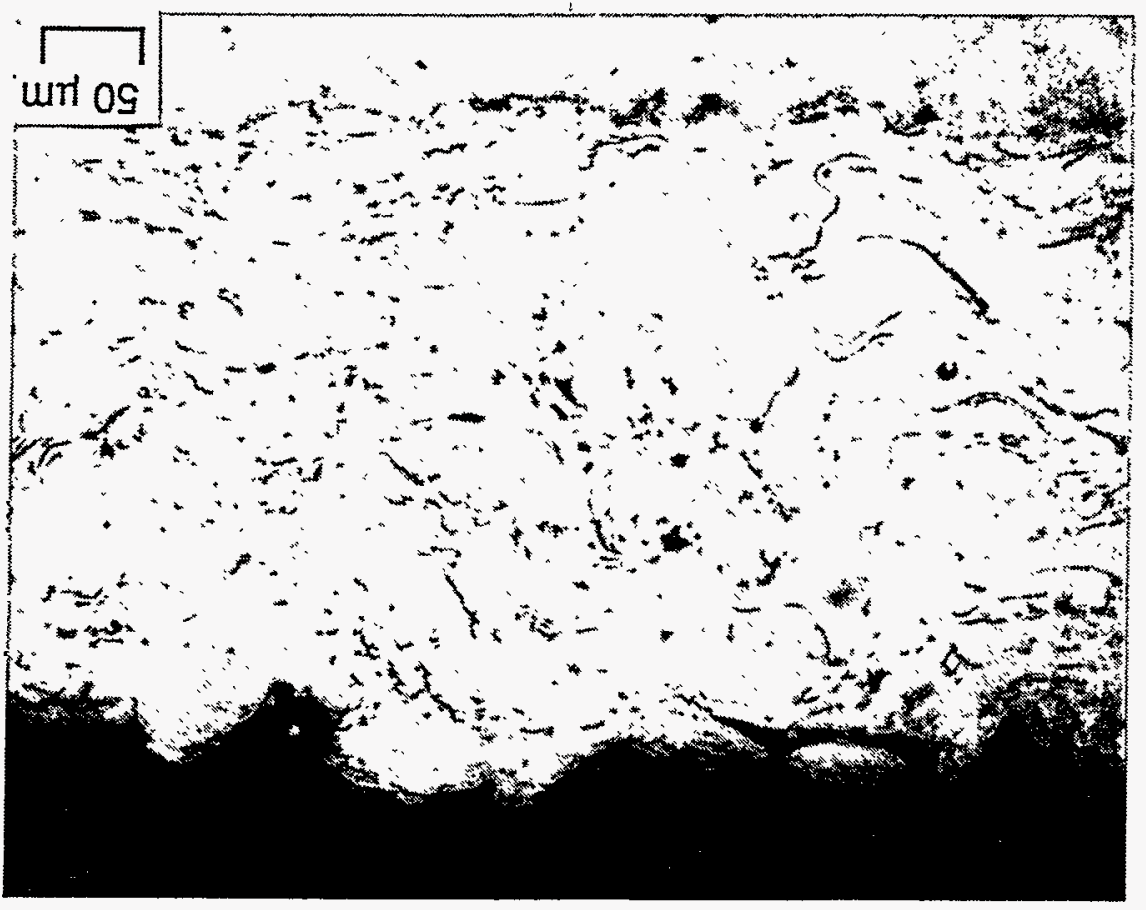


(i.e., I\% < $3 \%$ ) had minimal effect on the microhardness values.

Selection of the optimum levels of the design parameters can produce an optimum bond coating. This coating can be obtained by using an current of 300 amperes, a gun and shroud pressure of $50 \mathrm{psia}$ (air flow of $3060 \mathrm{scfh}$ ), and a spray distance of 3 in. However, the residual stresses in the coating produced with these parameters would not be minimized.

The Box evaluation employed in this study is significant in that it directs further experimentation while it considers the most important process or coating attributes and the process parameters that affect these attributes. The most important attributes may differ for the same material in different applications, and the baseline data generated in this study can be used to develop specific confirmation runs that approach the desired application attributes.

\section{Numerical Modeling of the Twin-Wire Electric Arc Process}

The Tafa TWEA gun generates a plasma concentrated at the intersection of the two feedwires. Modeling energy transport in this configuration requires solving the equations for mass, momentum, and energy conservation for both the arc and resulting plume. The calculated flow and temperature fields are then used to solve the gas/droplet interaction problem. Details, equations, input, and methodology for the models used in this study are discussed in References 5, 6, and 7. Air transport and thermodynamic properties were calculated from the Boltzmann equation using the theory of Chapman-Enskog-Bumett.(8)

The TORCH(6) code was used to model the energy transfer to the working gas, which resulted in the flow field file used for the gas-droplet analysis. Typical output from the TORCH model includes temperature, enthalpy, velocity, and viscosity profiles as a function of radial and axial position in the column and plume of the arc torch. The mass, momentum, and energy conservation equations are solved assuming a two-dimensional axisymmetric model. The flow field computation begins at the wire intersection location.

An energy balance was calculated at the wire intersection to calculate the initial state of the droplets. Losses to the input power included the amount of energy required to raise the wire to the melting point, the corresponding heat of fusion, cable voltage losses, energy loss to the ambient air, heat of vaporization considerations, and the degree of superheat in the droplets, which ranged from 247 to $290 \mathrm{~K}$ for the various experiments.

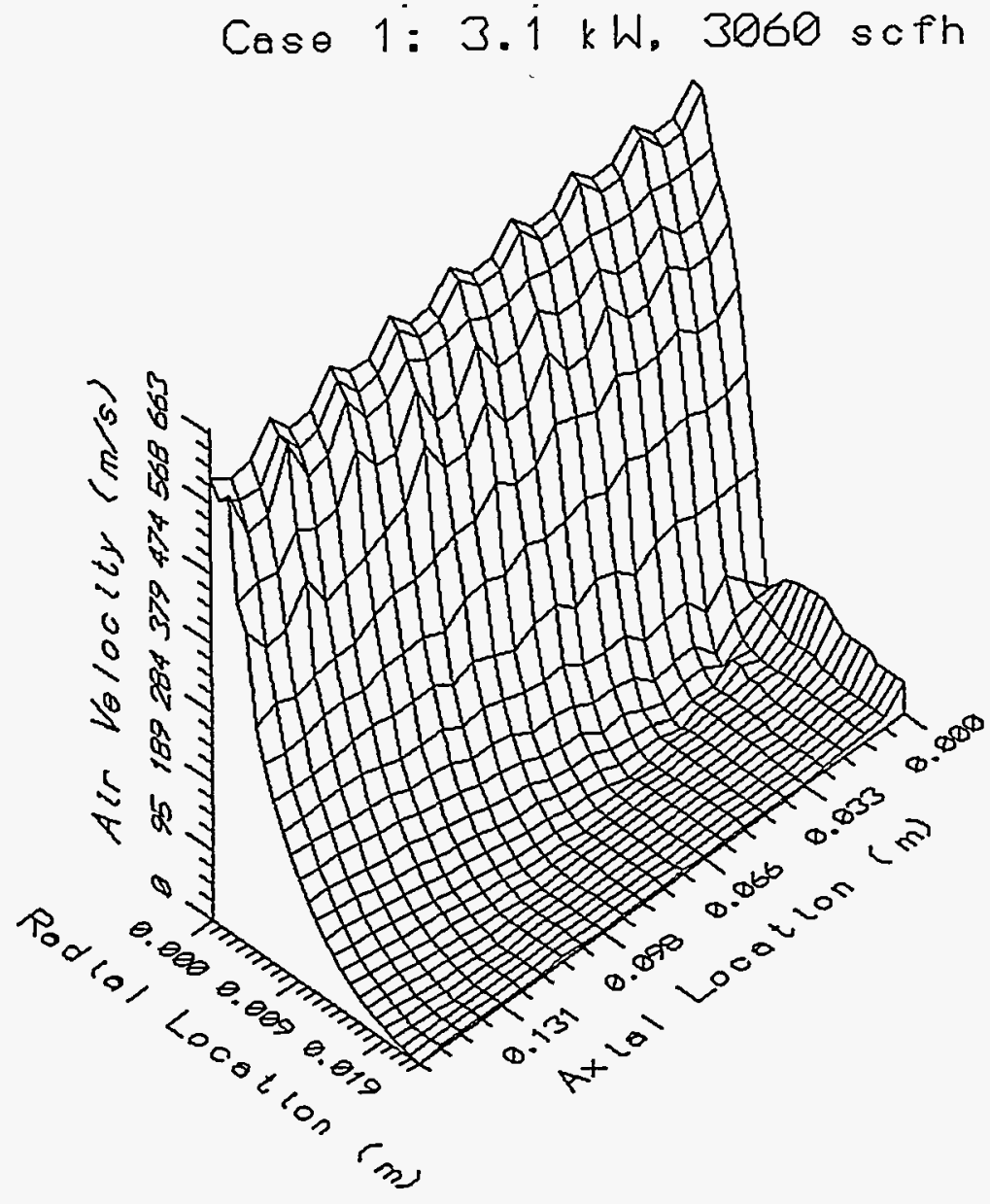

Figure 3. Predictions of the air velocity for experiment NA01. 
The numerical solutions describe the gas dynamics of the process in sufficient detail to allow a basic understanding of the process. Figure 3 illustrates the predictions of the air velocity for Experiment NA01 (i.e., Case $1, P=50$ psia, $Q$ $=3060 \mathrm{scfh}$ ). The maximum gas velocity is $670 \mathrm{~m} / \mathrm{s}$. This centerline gas velocity decreases over the length of the plume to approximately $500 \mathrm{~m} / \mathrm{s}$ respectively at the 6-in. spray distance. The sharp radial drop in velocity from the exit is due to the turbulent mixing with the ambient atmosphere. The amount of air entrain-ment increases substantially with increasing distance from the nozzle exit. For the higher pressure cases (i.e., $P=60$ and 70 psia, $Q=3,600$ and $4,200 \mathrm{scfh}$ ), the maximum gas velocities were 788 and $919 \mathrm{~m} / \mathrm{s}$. The average air temperature of the plume is predicted to be increased by less than $10 \mathrm{~K}$ for all the cases.

The PROCESS(7) code performed the gas-droplet interaction calculations for the TWEA model. The code uses the temperature and velocity fields generated by the TORCH code to calculate the dynamics of droplets injected into the plume. The primary result of the PROCESS code is a description of the injected droplet average temperature and velocity as a function of position in the gas. The droplets are assumed to be injected parallel to the plume.

The twin wires are located at the vena contracta of the 0.302-in. diameter orifice. At this location, the velocity of the flow is the highest and the maximum kinetic energy is available to atomize the molten metal. The diameters of the droplets stripped from the wires (i.e., $D_{0}$ ) is assumed to range from 15 to 300 microns. The TWEA breakup is envisioned as a one-step process in which droplets will not undergo further breakup. It is likely that several breakup mechanisms will exist simultaneously in the flow depending on the Weber number, including vibrational breakup, bag breakup, bag-andstamen breakup, sheet stripping, wave crest stripping, and catastrophic breakup.(9) The Weber number for the breakup of the initial droplet formed from the melting of metal electrodes indicates bag breakup is the predominant mechanism. A large number of small fragments are produced when the bag bursts and disintegrates, whereas only a few large fragments are produced when the rim decomposes. It is proposed that the fine range of the particles are the products of the bag breakup, while the coarse range are stable particles obtained when stripping stops and the remaining particle becomes too small to undergo further disintegration. Experimental data has shown a bimodal droplet size distribution for atomization resulting from bag breakup.(9) A large number of small droplets are produced when the bag bursts and disintegrates, whereas only a few large droplets are produced when the rim decomposes. The sheet droplet peak occurs at diameters less than $0.1 D_{0}$ (i.e., 15 microns) and the rim droplet peak occurs at diameters between 0.4 and $0.5 D_{0} .(10)$ After breakup, $88 \%$ of the droplets by number are approximately 15 microns in diameter. The normalized number distribution obtained from the data was integrated to obtain number percent, then converted to weight percent for use in the PROCESS code. Since the gas dynamics methodology in PROCESS does not account for primary breakup, secondary breakup, and coalescence in flight, the droplet sizes were held constant along the computed trajectories. The radial droplet distribution was scaled from experimental data found in the literature.(11) For a given droplet size, a maximum initial trajectory angle was scaled from the experimental data. The droplets were then linearly distributed from the flow centerline out to a maximum angle of 30 degrees off the plume centerline. Calculations were performed for metal droplet sizes of 15 to 225 microns in increments of 30 microns to study droplet morphology as a function of the process parameters for several experiments.

Nickel-aluminum begins melting at $1,726 \mathrm{~K}$. For Experiment NA01 at the wire intersection location, all of the droplet sizes are initialized at a temperature of $2,016 \mathrm{~K}$ due to the energy balance superheat assumption. The average temperature at the spray distance for each specific particle is a function of the heat transfer history to the particle, which is predicated by the unique trajectory of that particle. For this case, the amount of heat transfer to the droplets depends strongly on the particle size (i.e., surface-to-volume ratio) and the residence time of the droplets. Figures 4 and 5 illustrate the temperature and velocity predictions for the range of droplet sizes from 15 to 225 microns for a vector of 5 degrees off centerline. As shown in Figure 4, all of the droplets were predicted to exceed the melting point of nickel-aluminum for a significant portion of each droplet's trajectory. The droplets cool as they traverse through the plume. For this case, all of the droplets greater than 30 microns were in a superheated state at the 3-in. spray distance. As droplet size decreases, the surface-to-volume ratio becomes larger, and thus a larger total heat is removed from the droplets. Thus, the larger droplets maintain higher temperatures. As illustrated in Figure 5, the calculations indicate smaller droplets have higher velocity due to the larger acceleration forces. At the 3-in. spray distance, the particle velocities ranged from 65 to $200 \mathrm{~m} / \mathrm{s}$. As droplet size increases, the traversing droplets move radially outward from the centerline. The largest droplets traverse to the fringes of the gas plume, while the smaller droplets remain concentrated in the central portion of the spray.

Figures 6 and 7 illustrate the temperature and velocity predictions for a 75-micron droplet with a vector of 5 degrees off centerline for the range of conditions in the experimental matrix. As shown in Figure 6, as current increases, the droplet initial temperature decreases due to the lower meltpool superheat. For all cases, the particle cooled slowly throughout the trajectory while maintaining a droplet temperature greater than the melting point. As illustrated in Figure 7, as the air flow (i.e., pressure) increased, the droplet velocity increased.

It is interesting to note that although the higher-current experiments achieved slightly lower droplet temperatures, the $\mathrm{DE}$ for the experiments increases with increasing current. This is attributed to the fact that the lower-current experiments had a significantly higher total gas-flow to wire-feedrate ratio; this results in more entrainment of smaller droplets in the plume, that were cooler and resulted in more overspray. 


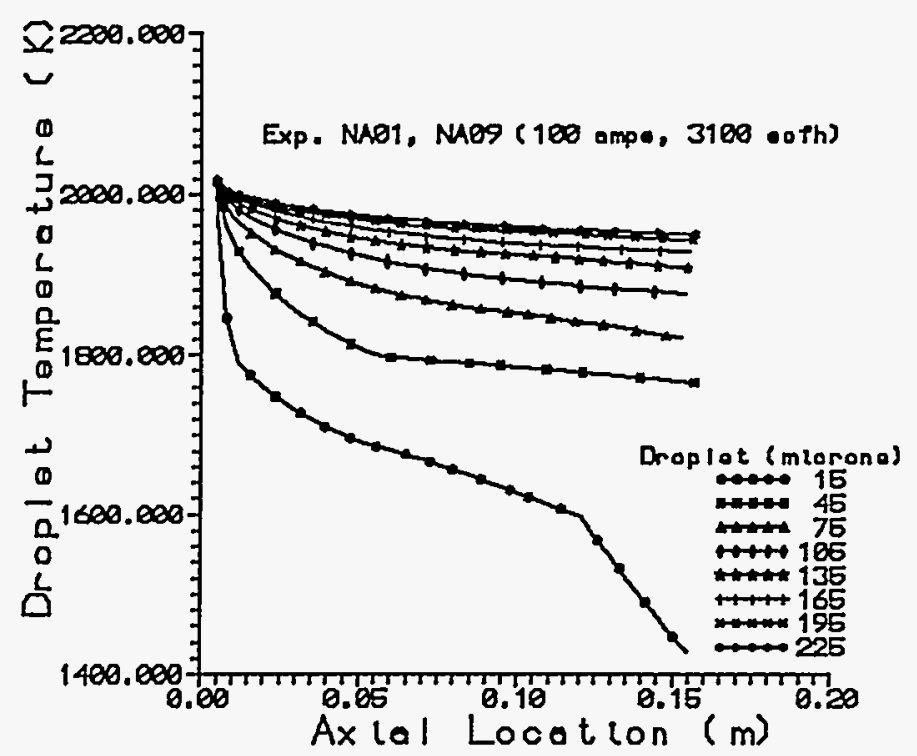

Figure 4. Temperature predictions for droplet sizes of 15-225 microns.

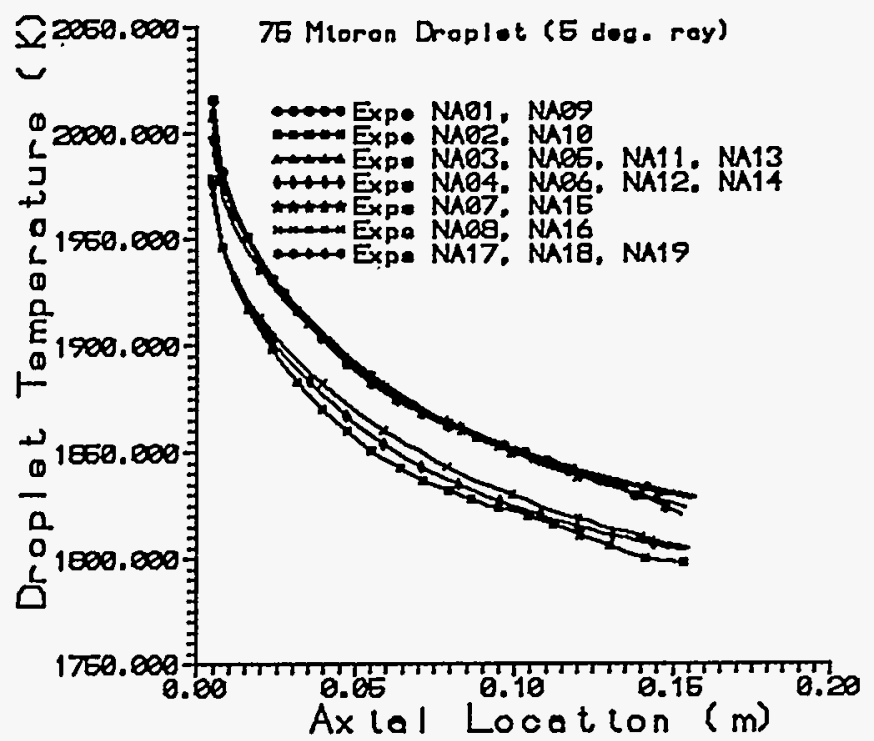

Figure 6. Temperature predictions for 75-micron droplets.

Also, the higher flow-to-wire mass ratio resulted in a wider plume angle, which enhanced cooling for all particle sizes. Surface roughness would also be expected to increase with the higher current experiments because of the greater number of larger particles impacting the substrate.

\section{Summary and Conclusions}

An experimental and analytical study of the twin-wire electric arc spraying of nickel-aluminum wire has been

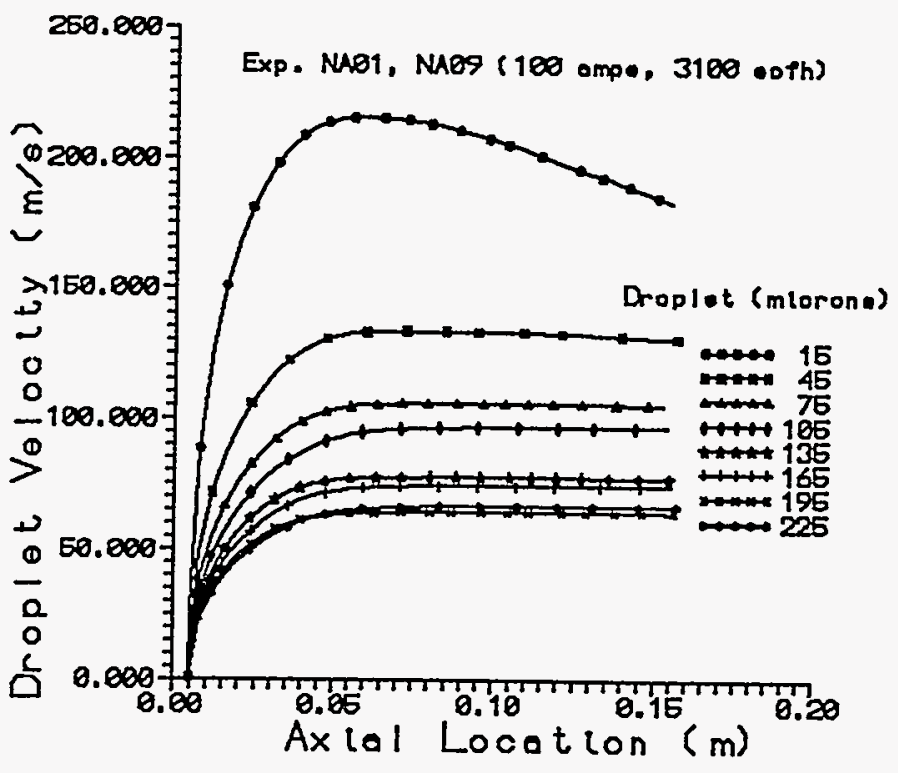

Figure 5. Velocity predictions for droplet sizes of 15-225 microns.

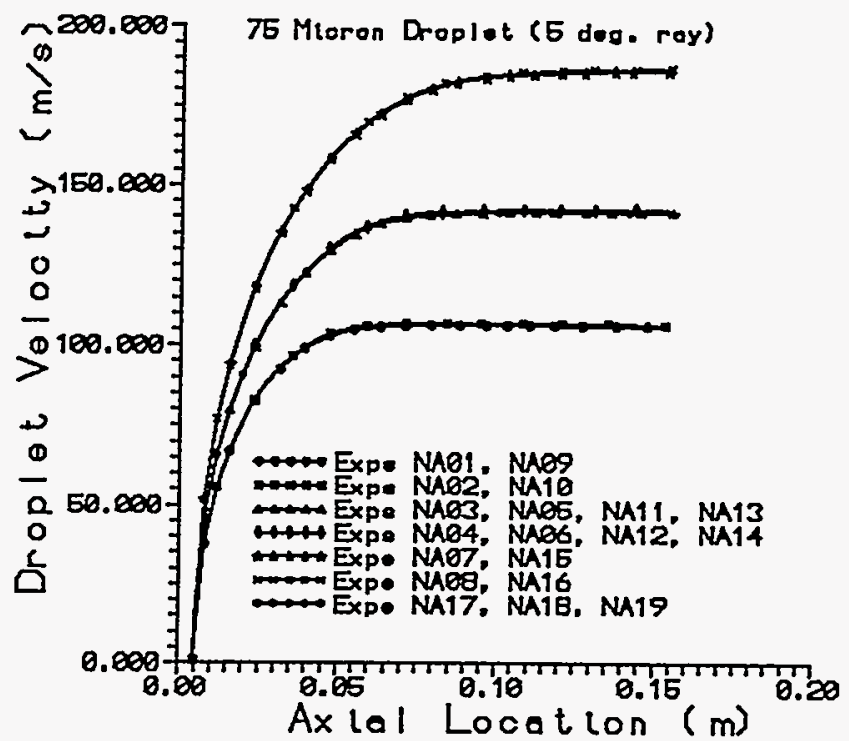

Figure 7. Velocity predictions for 75-microns droplets.

performed. A Box-type, full-factorial design of experiment was conducted. The process parameters varied were primary and secondary air flow, spray distance, and current. The resulting responses evaluated were thickness through optical microscopy, superficial hardness with a Rockwell $15 \mathrm{~N}$ test, microhardness with a Vickers test, porosity +oxide content with image analysis, coating roughness, and $D E$.

The nickel-aluminum coating porosity +oxide content, reflecting the influence of the process parameters, ranged from 7 to $19 \%$. The superficial Rockwell hardnesses ranged from 
55.3 to 76.9 , while the microhardness measurements ranged from 388 to 676 . DE for the experiments ranged from $\mathbf{5 5 . 8}$ to $76.9 \%$. The roughness of the coatings ranged from 388 to 676 microinches.

The statistical evaluation indicated that higher current and shorter spray distances result in higher $\mathrm{DE}$ and roughness. The evaluation indicated that higher current would result in higher microhardness. An optimum coating for this particular bond coat application can be obtained by using a current of 300 amperes, a gun and shroud pressure of 50 psia (air flow of $3060 \mathrm{scfh}$ ), and a spray distance of 3 in.

A numerical model of the process focused on gas and droplet dynamics. Air velocity increased with system pressure. The average plume air temperature was predicted to increase by only $10 \mathrm{~K}$ due to superheat added to the molten pool. Superheat in the molten pool ranged from 247 to $290 \mathrm{~K}$ for the experiments. Calculations were performed for droplet sizes of 15 to 225 microns. Smaller droplets cool substantially as they traverse through the plume. As the droplet diameter increases, the droplet maintains a higher temperature because of the lower surface-to-volume ratio. The calculations indicate that smaller droplets have higher velocity due to the larger acceleration from the drag forces at the liquid-gas interface. The DE for the experiments increased with increasing current due to the higher total gas-flow to wire-feedrate ratio and a wider plume angle that enhanced cooling. Surface roughness increased with higher current because of the greater number of larger particles impacting the substrate.

The range of coating attributes generated through the methodology presented in this paper serves to optimize the process and ultimately the coatings. From this statistical methodology, processing parameters can be adjusted, optimized, and confirmed; and, reliable and repeatable coating specifications can be established. Future work in this area will emphasize bond strength studies, different orifice configurations, analytical modeling of the coating dynamics, performance evaluation, and statistical correlation of the parameter-property-performance relationship.

\section{Acknowledgments}

Portions of the work described in this paper were supported by the U.S. Department of Energy, Assistant
Secretary for Defense, under DOE Contract No. DE-AC07$94 \mathrm{ID} 13223$.

The assistance of Professor E. Pfender of the University of Minnesota is gratefully acknowledged.

\section{References}

1. Kubel, E. D., Advanced Materials and Processes, 132, 69-80, (December 1987).

2. Box, G. E. P., W. G. Hunter, and J. S. Hunter, Statistics for Experimenters, John Wiley, New York, (1978).

3. Whitcomb, P., et al, Design-Ease, Version 2.0, Stat-Ease Incorporated, Minneapolis, MN 55413; Design-Ease is a registered trademark of Stat-Ease Incorporated.

4. Amin, M., The Welding Institute, Bulletin 3, 52-57, (May/June 1992).

5. D. J. Varacalle, Jr. et al., "Modeling Particulate Injection in Thermal Plasma Material Processing Experiments," The Metallurgical Society, The Reinhardt Schuhmann International Symposium on Innovative Technology and Reactor Design in Extraction Metallurgy, Colorado Springs, Colorado, USA, 501-518, (September 12, 1986).

6. Mazza, A., Studies of an Arc Plasma Reactor for Thermal Plasma Synthesis, Ph.D. Thesis, University of Minnesota (1983).

7. Lee, Y. C., Modeling Work in Thermal Plasma Processing, Ph.D. Thesis, University of Minnesota (1984).

8. I. O Hirschfelder, C. F. Curtiss, R. B. Bird, Molecular Theory of Gases and Liquids, John Wiley \& Sons, New York (1964).

9. Pilch, M., and C. A. Erdman, "Use of Breakup Time Data and Velocity History Data to Predict the Maximum Size of Stable Fragments for Acceleration-Induced Breakup of a Liquid Drop," International Journal of Multiphase Flow, 13, 6 (1987).

10. Komabayashi, M., Gonda, T., and Isono, K., J. Met. Soc. of Japan, 42, 330-340 (1964).

11. Mansour, A., and Chigier, N., "Disintegration of Liquid Sheets, " Phys. Fluids, A2 Vol. 5, 706 (May 1990).

\section{DISCLAIMER}

\begin{abstract}
This report was prepared as an account of work sponsored by an agency of the United States Government. Neither the United States Government nor any agency thereof, nor any of their employees, makes any warranty, express or implied, or assumes any legal liability or responsibility for the accuracy, completeness, or usefulness of any information, apparatus, product, or process disclosed, or represents that its use would not infringe privately owned rights. Reference herein to any specific commercial product, process, or service by trade name, trademark, manufacturer, or otherwise does not necessarily constitute or imply its endorsement, recommendation, or favoring by the United States Government or any agency thereof. The views and opinions of authors expressed herein do not necessarily state or reflect those of the United States Government or any agency thereof.
\end{abstract}

